\title{
Swash on a gently sloping beach
}

\author{
B. Raubenheimer and R. T. Guza \\ Center for Coastal Studies, Scripps Institution of Oceanography, La Jolla, California
}

Steve Elgar

Electrical Engineering and Computer Science, Washington State University, Pullman

\author{
N. Kobayashi \\ Department of Civil Engineering, University of Delaware, Newark
}

\begin{abstract}
Waves observed in the inner surf and swash zones of a fine grained, gently sloping beach are modeled accurately with the nonlinear shallow water equations. The model is initialized with observations from pressure and current sensors collocated about $50 \mathrm{~m}$ from the mean shoreline in about $1 \mathrm{~m}$ depth, and model predictions are compared to pressure fluctuations measured at five shoreward locations and to run-up. Run-up was measured with a vertical stack of five wires supported parallel to and above the beach face at elevations of $5,10,15,20$, and 25 cm. Each 60-m-long run-up wire yields time series of the most shoreward location where the water depth exceeds the wire elevation. As noted previously, run-up measurements are sensitive to the wire elevation owing to thin run-up tongues not measured by the more elevated wires. As the wire elevation increases, the measured mean run-up location moves seaward, low-frequency (infragravity) energy decreases, and higher-frequency sea swell energy increases. These trends, as well as the variation of wave spectra and shapes (e.g., wave skewness) across the inner surf zone, are well predicted by the numerical model.
\end{abstract}

\section{Introduction}

Miche [1951] hypothesized that run-up, the timevarying location of the shoreward edge of the swash on the beach face, results from standing waves formed by the reflection of wave energy reaching the shoreline. Shoreward propagating energy exceeding a threshold value was assumed to be dissipated by wave breaking. The threshold value for normally incident monochromatic waves on a planar beach was subsequently derived from the depth-averaged nonlinear shallow water equations [Carrier and Greenspan, 1958]. Laboratory studies [e.g., Moraes, 1970; Guza and Bowen, 1976] confirmed that the maximum amount of reflected monochromatic wave energy and the associated run-up excursions increase with increasing beach slope and decrease with increasing wave frequency, with approximately the functional dependence suggested by Miche [1951].

Field observations show that random waves follow similar trends. Reflected wave and run-up energies at sea swell frequencies (nominally $0.05-0.40 \mathrm{~Hz}$ on ocean

Copyright 1995 by the American Geophysical Union.

Paper number $95 \mathrm{JC} 00232$.

0148-0227/95/95JC-00232\$05.00 beaches) increase with increasing beach slope, and reflection at infragravity frequencies (nominally 0.001$0.05 \mathrm{~Hz}$ ) is stronger than at higher sea swell frequencies [Suhayda, 1974; Huntley, 1976; Huntley et al., 1977; Guza and Thornton, 1985b; Holman and Sallenger, 1985; Elgar et al., 1994]. On low-slope ocean beaches the run-up is often dominated by infragravity waves, with relatively little energy at sea swell frequencies which dominate sea surface elevation spectra farther seaward.

In the present study, predictions of a numerical model [Hibberd and Peregrine, 1979; Packwood, 1980; Kobayashi et al., 1989] based on the depth-averaged nonlinear shallow water equations with bottom friction are compared to observations in the surf and swash zones of a gently sloping beach. In a previous study [Kobayashi and Wurjanto, 1992], run-up variance observed on both a barred and a planar beach was qualitatively predicted given approximated (for lack of detailed data) model initial conditions (e.g., properties of the incident wave field). Here the model, initialized with observations in about $1 \mathrm{~m}$ depth, predicts accurately the variation of wave spectra and wave shape across the inner surf zone, as well as in the swash (where run-up was observed with a new multilevel wire sensor described below).

The observations and numerical model are briefly discussed in sections 2 and 3 , respectively. Model-data 
comparisons are presented in section 4, followed by a discussion (section 5) and conclusions.

\section{Observations}

Instruments were deployed on a transect across the fine-grained, gently sloping Scripps Beach (Figure 1a). Six pressure sensors were located seaward of the swash zone in mean depths between 20 and $80 \mathrm{~cm}$, an electromagnetic current meter was collocated with the most offshore pressure gage (where the numerical model is initialized), and five resistance run-up wires, stacked vertically with the bottom wire $5 \mathrm{~cm}$ above the bed and $5 \mathrm{~cm}$ separation between wires, were deployed parallel to the beach face (Figure 1a). Nonconducting supports placed every few meters were frequently adjusted to maintain constant wire elevation above the sand. Runup wire calibrations, completed prior to the experiment by submerging known lengths of wire in a large basin, show the accuracy is approximately $\pm 3 \mathrm{~cm}$ along the wire. Further information about run-up wire measure-

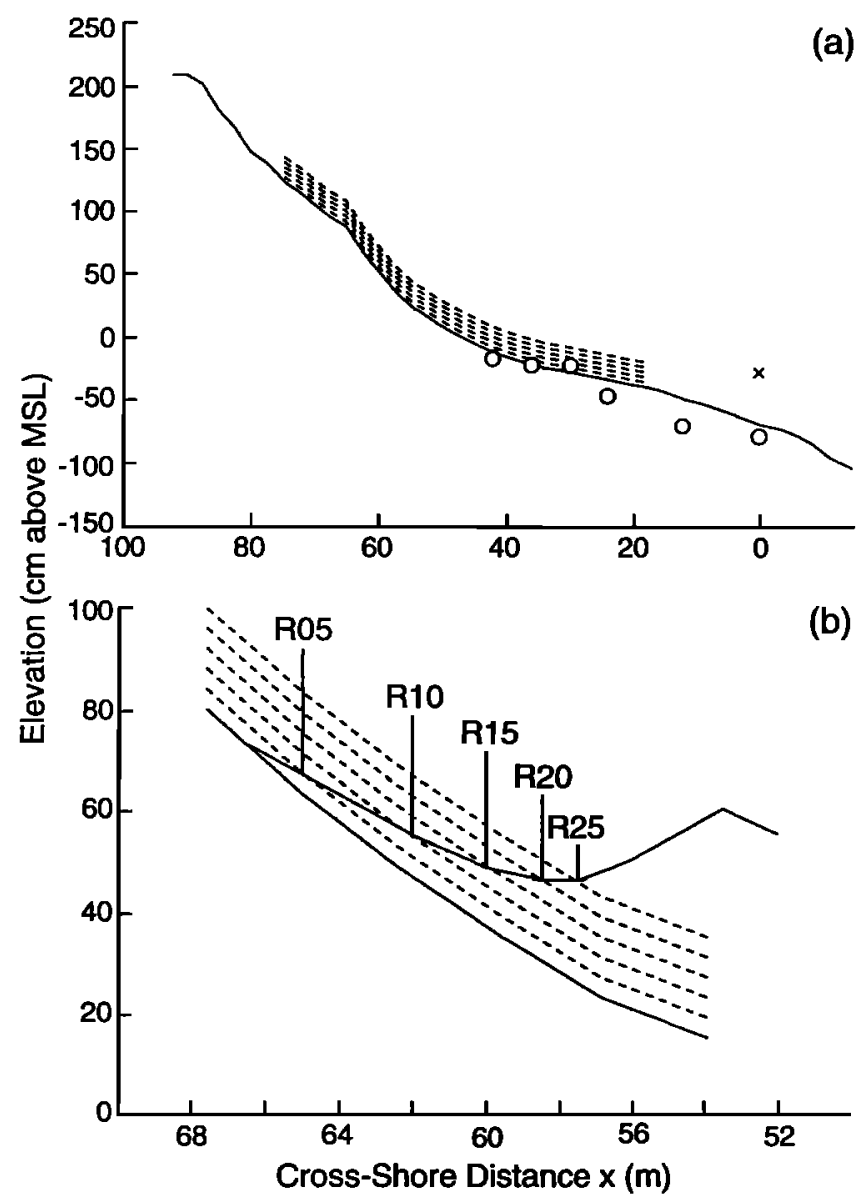

Figure 1. (a) June 28 beach profile (solid curve) and instrument locations: current meter (cross), pressure sensors (open circles), and run-up wires (dashed lines). (b) Schematic illustration showing instantaneous runup locations measured by each wire. The $x$ axis, positive onshore, is zero at the sensor location where the numerical model is initialized. ments is given by Holman and Guza [1984] and Holland et al. [1995].

Each run-up wire measures the most shoreward location at which the water depth exceeds the wire elevation. Wire measurements of the cross-shore run-up location were converted to vertical run-up using the known wire height and beach profile. By combining simultaneous measurements from all five wires, the instantaneous shape and location of the swash front can be estimated (e.g., Figure 1b). Run-up wires will be identified by their elevation (in centimeters) above the bed (e.g., R05 and R25 are the bottom and top wires, respectively). Pressure sensors will be identified by their distance (in meters) from the most offshore pressure gage (e.g., the most offshore and shoreward gages are $\mathrm{P0}$ and P42, respectively). Sea surface elevations were estimated using the assumption that the measured pressure field is hydrostatic.

Six data runs, from 0.9 to 1.5 hours long, were acquired at an $8-\mathrm{Hz}$ sample rate during 4 days in June 1989. The data were quadratically detrended to remove tides and other motions with periods longer than roughly 1 hour. Beach slopes in the swash region, measured daily, ranged from 0.030 to 0.043 depending on tidal stage, and the offshore slope was approximately 0.010. Offshore (approximately $7 \mathrm{~m}$ depth) significant wave heights ranged from 50 to $82 \mathrm{~cm}$, and peak wave periods were approximately $10 \mathrm{~s}$. Holland et al. [1995] gave an additional description of the experiment and compared multilevel wire and video run-up measurements.

\section{Model}

Wave propagation in shallow water and the subsequent run-up have been modeled with the onedimensional depth-averaged nonlinear shallow water equations with quadratic friction,

$$
\begin{gathered}
\frac{\partial h}{\partial t}+\frac{\partial}{\partial x}(h u)=0 \\
\frac{\partial}{\partial t}(h u)+\frac{\partial}{\partial x}\left(h u^{2}\right)=-g h \frac{\partial \eta}{\partial x}-\frac{1}{2} f_{c}|u| u
\end{gathered}
$$

where $t$ is time, $x$ is the distance onshore from the model seaward boundary, $h=d+\eta$ is the total water depth, $\eta=\tilde{\eta}+\bar{\eta}$ is the sum of the oscillatory sea surface elevation $(\tilde{\eta})$ and the mean $(\bar{\eta})$ deviation from the still water depth $d, u=\tilde{u}+\bar{u}$ is the sum of the oscillatory ( $\tilde{u})$ and mean $(\bar{u})$ components of the depth-averaged crossshore velocity, $g$ is gravitational acceleration, and $f_{c}$ is a constant empirical friction coefficient. Hibberd and Peregrine [1979] showed that model solutions obtained with $f_{c}=0$ and a Lax-Wendroff numerical scheme [Lax and Wendroff, 1960] reproduced analytic run-up solutions for both a finite-amplitude standing wave [Carrier and Greenspan, 1958] and a single bore [Keller at al., 1960; Shen and Meyer, 1963]. The Lax-Wendroff method spreads the bore front across a few horizontal grid points and implicitly introduces dissipation ap- 
proximately equal to the theoretical dissipation for a bore given conservation of mass and momentum [Ritchmyer and Morton, 1967; Ames, 1969]. Although details of the bore front may be unrealistic because the the model assumptions may be locally violated, the solutions are otherwise valid if the shock front covers a relatively small distance and is nearly vertical [Meyer and Taylor, 1972; Synolakis, 1987]. Although the analytic and numerical (with $f_{c}=0$ ) results for a single bore are quite similar, both significantly overpredict the maximum run-up observed in the laboratory. Inclusion of a friction term reduces the maximum predicted runup to near observed values but has little effect seaward of the swash zone [Packwood, 1980].

Following Hibberd and Peregrine [1979] and Packwood [1980], Kobayashi and colleagues have developed a numerical model based on (1) and (2) (hereinafter called Rbreak [see Wurjanto and Kobayashi, 1991]) that predicts the evolution of random waves propagating over irregular (in the cross-shore direction) bathymetry. On the basis of previous calibrations and additional model tests a friction coefficient of $f_{c}=0.015$ was used here. The model results shown below are not sensitive to the value of $f_{c}$ in the range $.01 \leq f_{c} \leq .05$ (see Appendix).

Rbreak assumes hydrostatic pressure and uniform velocity over the vertical, an impermeable beach and homogeneous bathymetry in the longshore, and normally incident waves. Madsen and Svendsen [1983] showed that the hydrostatic assumption is approximately valid in the surf zone. The field data were collected near midtide when the fine-grained Scripps Beach is saturated, so the assumption of an impermeable beach may be approximately satisfied. Sea swell waves, which have propagated shoreward from deep water, are nearly normally incident in the surf zone owing to refraction. However, low-mode edge-wave energy at infragravity frequencies can be significant in very shallow water [e.g., Oltman-Shay and Guza, 1987] and could cause discrepancies between model predictions and observations [Holland et al., 1995]. Further discussion of the model assumptions is given by Kobayashi and Wurjanto [1992]. One result of the present study is that these simplifications and assumptions do not substantially degrade the performance of Rbreak relative to its performance in a narrow laboratory flume with normally incident waves over an impermeable bed [Kobayashi et al., 1990; Wise et al., 1991; Cox et al., 1992].

\section{Model-Data Comparisons}

Rbreak is initialized at the seaward model boundary with time series of sea surface elevation corresponding to the shoreward propagating wave field. The shoreward (and seaward) propagating wave fields are estimated using collocated pressure and current meters in conjunction with linear, long-wave theory in slowly varying depth and the assumption of shore-normal wave propagation. In this case the incident and reflected waves, $\tilde{\eta}_{i}$ and $\tilde{\eta}_{r}$, respectively, are approximately $[\mathrm{Na}$ gata, 1964; Guza et al., 1984; List, 1992],

$$
\begin{aligned}
& \tilde{\eta_{i}}=\frac{1}{2}\left(\tilde{\eta}+\tilde{u} \sqrt{\frac{\bar{h}}{g}}\right) \\
& \tilde{\eta_{r}}=\frac{1}{2}\left(\tilde{\eta}-\tilde{u} \sqrt{\frac{\bar{h}}{g}}\right)
\end{aligned}
$$

where $\bar{h}=d+\bar{\eta}$ is the total mean water depth (including setup) and $\tilde{\eta}=\tilde{\eta}_{i}+\tilde{\eta}_{r}$ is the total oscillatory sea surface displacement. Rbreak is initialized with $\tilde{\eta}_{\boldsymbol{i}}$ calculated (using (3)) from observations made in approximately 1 m depth (Figure 1a).

The reflected wave at the seaward boundary of the model is predicted using the characteristic form of the inviscid $\left(f_{c}=0\right)$ nonlinear shallow water equations (frictional dissipation has negligible effect on model predictions at this depth [Kobayashi and Wurjanto, 1992]). The observed squared reflection coefficient $\left(R^{2}(f)\right)$, defined as the ratio of the reflected to incident wave energies, is based on the observed $\tilde{\eta}_{i}$ (3) and $\tilde{\eta}_{T}$ (4), whereas the predicted $R^{2}(f)$ uses the predicted $\tilde{\eta}_{r}$. At the seaward boundary, both the observed and predicted $R^{2}(f)$ are typically near unity at very low frequencies and are small at swell frequencies (Figure 2). Note that, owing to wave breaking induced dissipation of shoreward progressive waves, the relative amount of reflected energy increases shoreward, and $R^{2}(f)$ is expected to vary with cross-shore position.

Rbreak accurately predicts many aspects of the observed wave transformation and run-up. For instance, the model predicts the observed decrease in the number of individual bores as waves propagate shoreward (e.g., compare Figures $3 a$ and $3 b$ ), the intermittent exposure of the beach face during swash downwashes (Figure 3c),

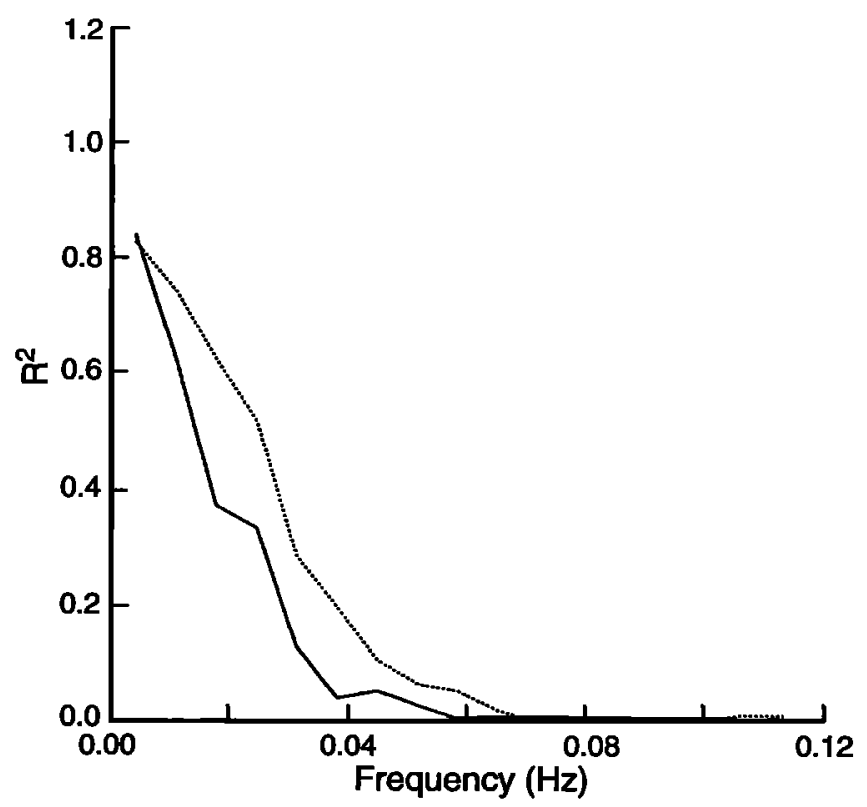

Figure 2. Predicted (solid line) and observed (dotted line) squared reflection coefficient $R^{2}(f)$ versus frequency, $f$, at $\mathbf{P 0}$ for the 1228 data run (foreshore slope 0.030 ). Run names correspond to the starting hour and day of each data record. 


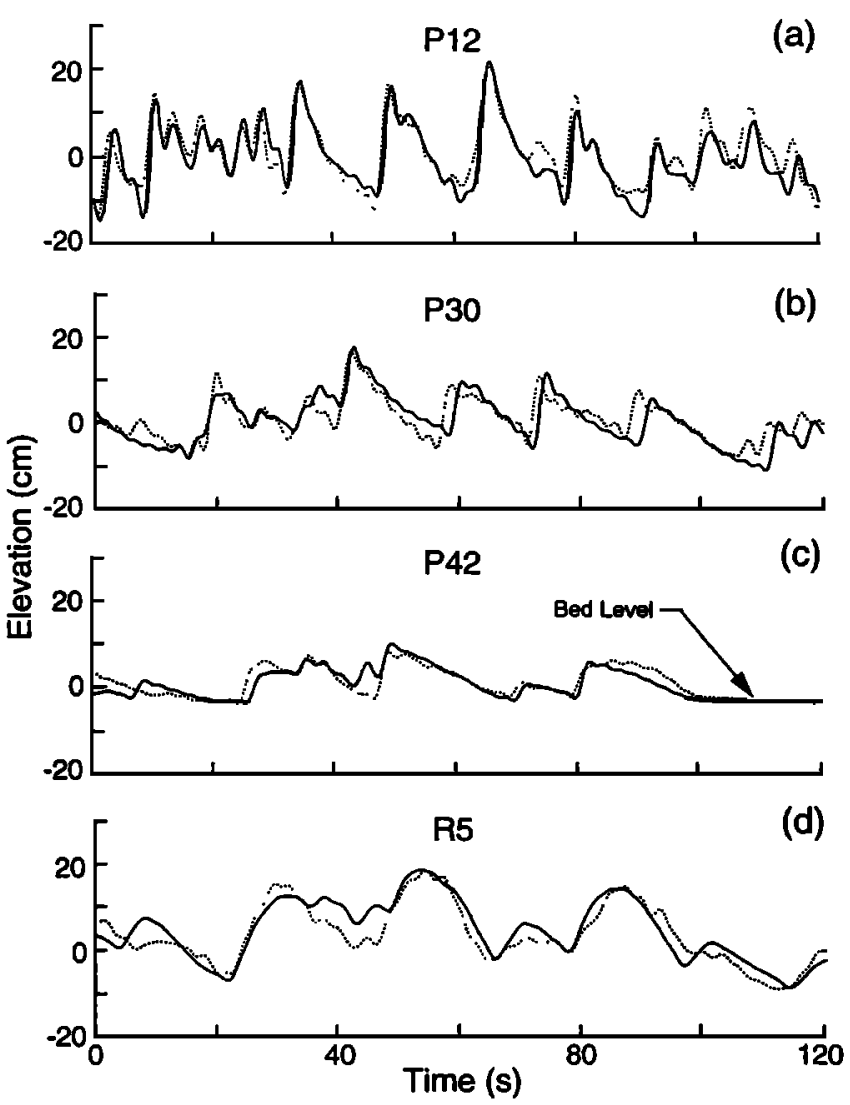

Figure 3. Predicted (solid line) and observed (dotted line) demeaned time series of sea surface elevation during run 1228 at cross-shore locations (a) $12 \mathrm{~m}$, (b) 30 $\mathrm{m}$, and (c) $42 \mathrm{~m}$ (the water level in the saturated sand above the buried pressure sensor remains constant when the beach face is exposed during downwashes) and (d) of run-up $5 \mathrm{~cm}$ above the bed (mean horizontal location $42 \mathrm{~m})$.

and the dominance of infragravity waves in the run-up (Figures 3d and 6a). Measured and predicted shapes of a typical swash front (constructed, as in Figure 1b, using observations and model results for the same five elevations) are shown in Figure 4. Similar to previously reported model-data comparisons of solitary wave runup [Synolakis, 1987], the predicted bore front lags behind and is steeper than the observations (Figure 4b), but the maximum uprush and concave shape during downwash are well modeled (Figures 4c-4e). Run-up predicted at the elevation of the highest wire $(25 \mathrm{~cm})$ is usually located seaward of the run-up predicted at the lowest elevation $(5 \mathrm{~cm})$, as is observed (Figure 4). Therefore the observed and predicted mean horizontal run-up locations move shoreward with decreasing wire elevation (Figure 5a). Owing to the thin concave runup tongues (e.g., Figures $4 c$ and $4 d$ ) the mean observed and predicted vertical run-up locations increase with decreasing wire height (Figure $5 \mathrm{~b}$ ). As the wire elevation decreases, the observed increase in total (i.e., combined sea swell and infragravity frequency bands) vertical run-up variance at each wire is also predicted accurately (Figure $5 c$ ).

The observed increase of infragravity energy and de-

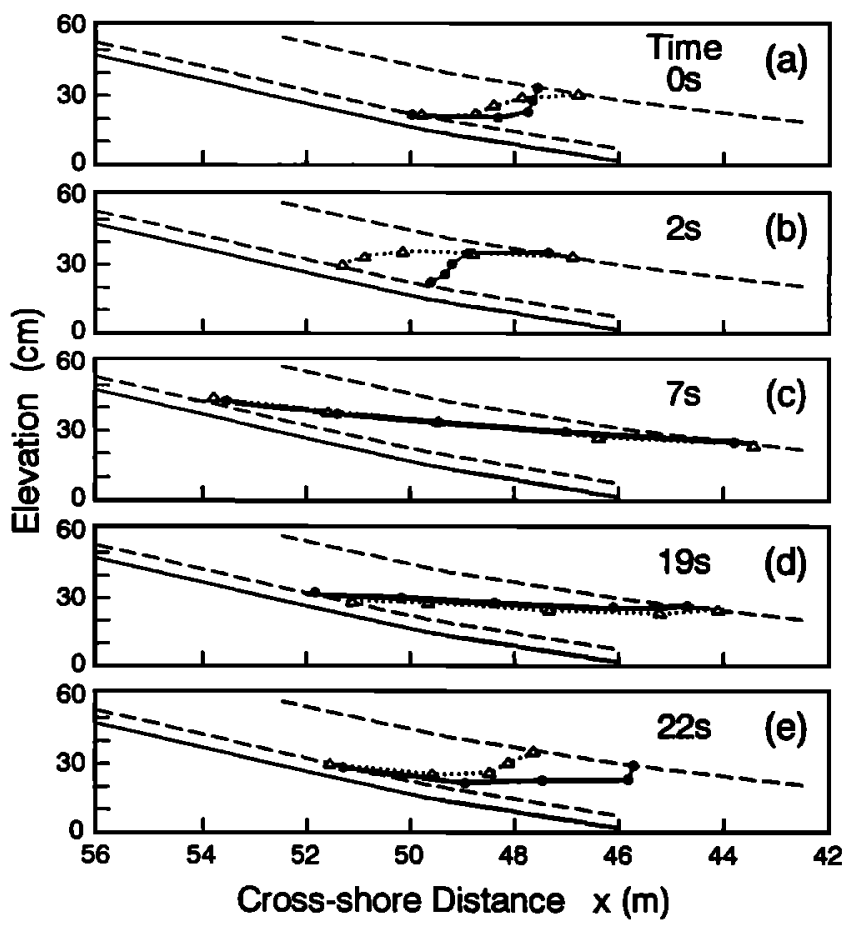

Figure 4. Predicted (solid circles connected by solid lines) and observed (open triangles connected by dotted lines) instantaneous swash front positions during run 1228 at times (a) 0 (when a bore begins moving up the beach), (b) 2 , (c) 7, (d) 19, and (e) $22 \mathrm{~s}$. The dashed lines indicate the elevations of the top and bottom wires, and the lowermost solid lines are the beach face.

crease of sea swell energy at the lowest wire, relative to both the initial conditions and the higher wires, are predicted (Figure 6a). The high coherence and substantial phase lags observed between two run-up wires (Figures $6 \mathrm{~b}$ and $6 \mathrm{c}$ are representative) are also predicted accurately. The coherence between predicted and observed run-up at each wire elevation is high and the phase difference is nearly zero (not shown).

The predicted and observed cross-shore evolution of surf zone sea surface elevation and run-up variance, integrated over each of four frequency bands, is shown for two consecutive data runs (Figure 7a-7h), spanning a 3hour period during which the offshore significant wave height $(\approx 82 \mathrm{~cm})$ was approximately constant while the foreshore slope increased because the tide was rising. In both runs, the predicted and observed variance in the frequency band $0.001 \leq f \leq 0.05 \mathrm{~Hz}$ increases significantly in the run-up, reaching a maximum at the lowest wire, which corresponds to the most shoreward sensor location (Figures $7 \mathrm{a}$ and $7 \mathrm{~b}$ ). The variance in the highest frequency band $(0.12<f \leq 0.40 \mathrm{~Hz})$ decreases across the surf zone to near zero in the run-up (Figures $7 e$ and $7 f)$. The cross-shore evolution of variance in the midfrequency band $(0.05<f \leq 0.12 \mathrm{~Hz})$ suggests a dependence on the foreshore slope (Figures 7c and 7d). For a foreshore slope of 0.030 (Figure 7c) the midfrequency energy monotonically decreases shoreward. 


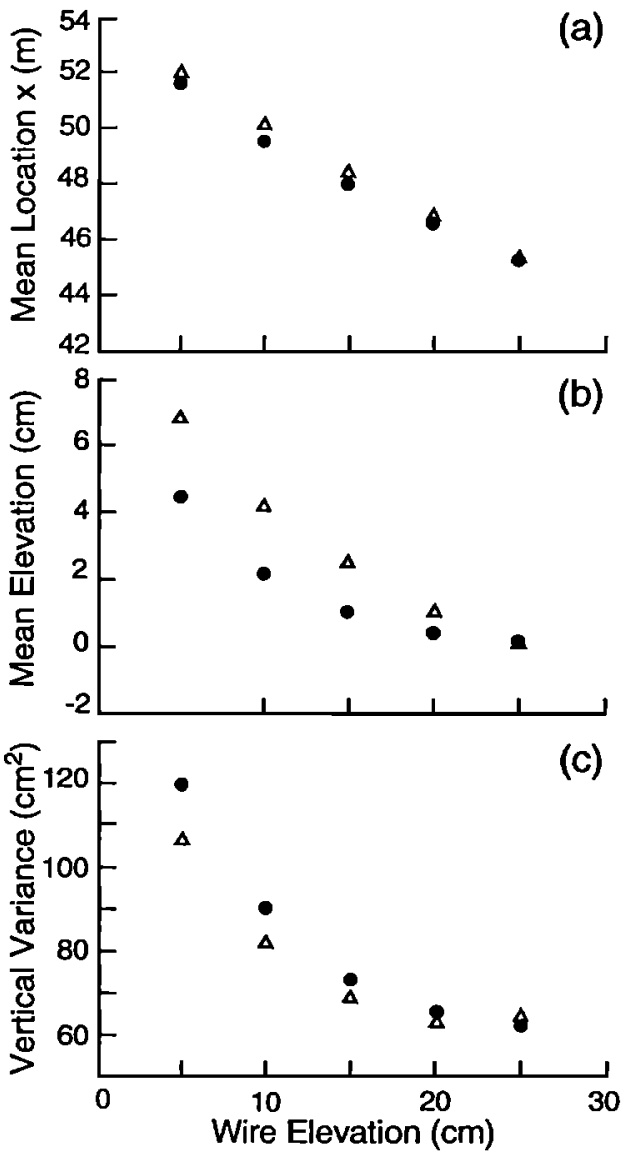

Figure 5. For each wire height (for run 1228), predicted (solid circles) and observed (open triangles) (a) mean cross-shore run-up location, (b) mean vertical run-up elevation relative to the mean vertical elevation at R25, and (c) vertical run-up variance versus wire elevation.

However, when the foreshore slope is steeper (Figure $7 \mathrm{~d}$, slope $=0.039$ ), the predicted and observed midfrequency energy decreases across the surf zone but then increases very near the shoreline (i.e., the bottom two run-up wires). Changes in the total variance (Figures $7 \mathrm{~g}$ and $7 \mathrm{~h}$ ) with decreasing depth (and wire elevation) depend on the relative magnitudes of energy increases resulting from shoaling of nonbreaking waves (e.g., Figures $7 \mathrm{a}$ and $7 \mathrm{~b}$ ) and energy dissipation primarily owing to breaking (Figures 7e and 7f). Across the surf zone, the decrease in sea swell energy (breaking) exceeds the increase in infragravity energy (shoaling), and the total variance decreases in the shoreward direction. Near the shoreline, the increase in infragravity energy with decreasing depth and wire elevation is apparently greater than the dissipation of sea swell energy, resulting in a total variance minimum at approximately the seaward edge of the swash zone (Figures $7 \mathrm{~g}$ and $7 \mathrm{~h}$ ).

The agreement between model predictions and observations for all six runs (Figure 8 ) is similar to the two data runs shown in Figure 7. Sea surface variance is usually slightly overpredicted at infragravity frequencies (Figure 8a) and slightly underpredicted at high frequencies (Figure 8c). The errors partially cancel such that the total predicted variance is typically within $20 \%$ of the observations (Figure 8d).

Phase differences between observations at different locations within the surf and swash zones are well predicted (Figure 9 is typical). For a pure standing wave (e.g., $R^{2}=1.0$ ) the phase difference between measurements at any two locations is either 0 or $180^{\circ}$. In contrast, for a wave propagating only in the shoreward direction (e.g., $R^{2}=0.0$ ), the phase difference between offshore sea surface fluctuations and run-up increases smoothly with offshore distance. Consistent with the high predicted and observed $R^{2}$ at low frequencies at the initial condition (Figure 2), the predicted and observed phase difference (relative to the lowest run-up wire) at low frequency is nearly zero for all swash and surf zone sensors (Figure 9a; $f=0.006 \mathrm{~Hz}$ for which $R^{2} \approx 0.8$ ). At somewhat higher frequency (Figure 9b; $f=0.035$ $\mathrm{Hz}, R^{2} \approx 0.25$ ) the phase increases continuously with offshore distance, but phase jumps are also apparent at approximately $x=40$ and $10 \mathrm{~m}$, as expected when waves are partially reflected so that both progressive and standing components are significant. Near the swell peak frequency, the phase varies smoothly with no obvious phase jumps (Figure 9c; $f=0.084 \mathrm{~Hz}$ ), consistent with the primarily progressive wave field indicated by

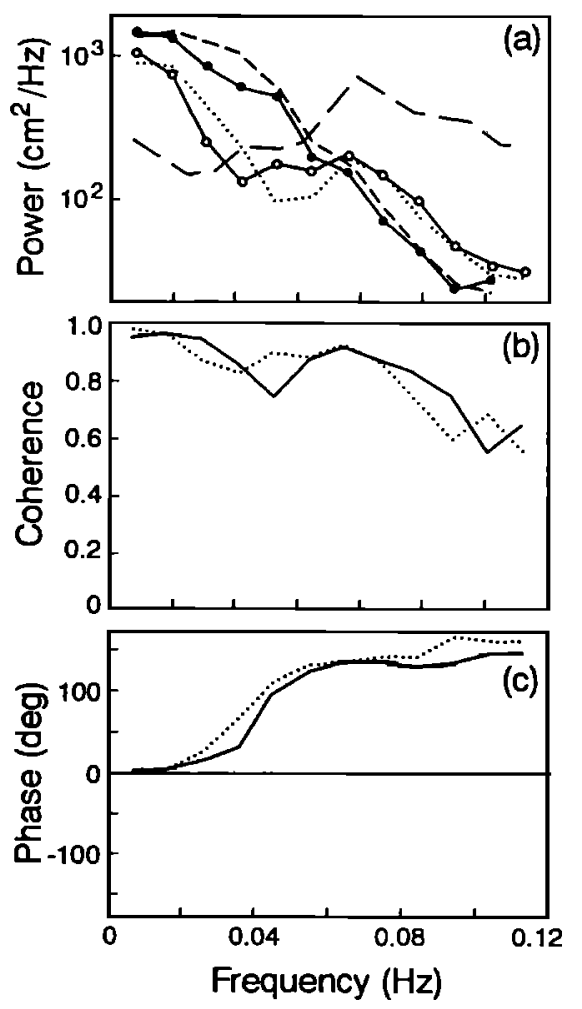

Figure 6. (a) For run 1228, observed spectrum at the initial condition P0 (long-dashed line), R15 (dotted line), and R05 (short-dashed line). Predicted spectra are shown for R15 (solid line with open circles) and R05 (solid line with solid circles). (b) Coherence and (c) phase between R15 and R05 (observed, dotted line; predicted, solid line). There are $60^{\circ}$ of freedom, and the $95 \%$ significant coherence level is about 0.3 . 


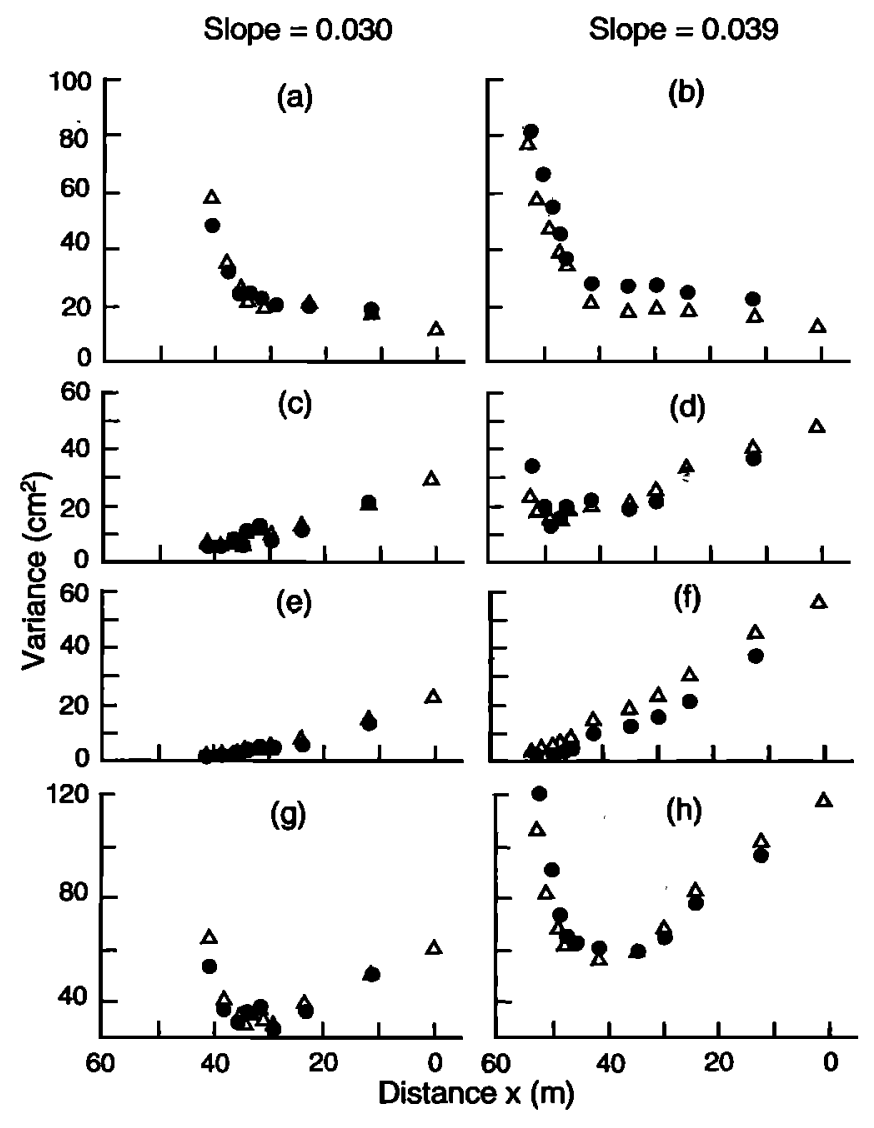

Figure 7. Predicted (solid circles) and observed (open triangles) band-passed variance for all pressure sensors and run-up wires versus cross-shore distance for two consecutive data runs with foreshore slopes 0.030 , (run 1228, left panels) and 0.039 , (run 1328, right panels). Frequency band-pass ranges are (a-b) $0.001 \leq f \leq 0.05$ $\mathrm{Hz}$, (c-d) $0.05<f \leq 0.12 \mathrm{~Hz}$, (e-f) $0.12<f \leq 0.40 \mathrm{~Hz}$, and (g-h) $0.001 \leq \bar{f} \leq 0.40 \mathrm{~Hz}$. For each run-up wire, the predicted (or observed) vertical variance is plotted at the predicted (or observed) mean cross-shore runup location. Thus the most shoreward sensor location corresponds to the lowest wire, R05. The variance at P42, the most shoreward pressure sensor, is not shown in run 1228 because the beach face at this location was uncovered during downwashes (e.g., Figure 3c).

the small $R^{2}(\approx 0)$ at the initial condition (Figure 2$)$.

Bulk properties of the observed asymmetrical wave shapes (Figure 3) are quantified by the wave skewness and asymmetry. Positive wave skewness results from the peakedness of wave crests relative to the flatter troughs, whereas positive asymmetry results from front wave faces which are pitched forward relative to the more gently sloped rear faces [Masuda and Kuo, 1981]. The present observations in the inner surf zone are similar to previous observations [Elgar and Guza, 1985; Guza and Thornton, 1985a; Elgar et al., 1990] and also extend into the swash zone. The predicted and observed sea swell skewness (i.e., the skewness of time series band-passed in the sea swell frequency range, $0.04-0.4 \mathrm{~Hz}$ ) is positive, small, and nearly constant until the swash where it is negative and small (Figure 10a).
The sea swell asymmetry increases shoreward, is maximum at the shallowest pressure sensor, and then drops to approximately zero in the run-up (Figure 10c). The steep, asymmetric front faces of bores measured by fixed pressure sensors do not produce comparable asymmetries in the run-up wire observations.

The infragravity band, which is relatively energetic in the inner surf and swash zones, affects wave skewness and asymmetry. The predicted and observed total (i.e., both infragravity and sea swell frequency bands) skewness is small, positive, and nearly constant across both the surf and swash zones (Figure 10b). The predicted and observed total asymmetry is smaller than the sea swell asymmetry and reaches a maximum farther seaward (Figure 10d).

\section{Discussion}

The qualitative agreement between an inviscid, linear standing wave model and observations of run-up and surf zone pressure and velocity fluctuations at infragravity frequencies noted in both previous [e.g., Suhayda, 1974] and the present [Holland et al., 1995] data sets is not inconsistent with the present agreement between observations and predictions from a dissipative nonlinear model (e.g., Figures 3-9). Although the cross-shore energy variation (Figure 7a-7b) and phase structure (Figure 9a-9b) at infragravity frequencies predicted by the nonlinear model are not identical to linear model predictions, they are similar. For example, the loca-

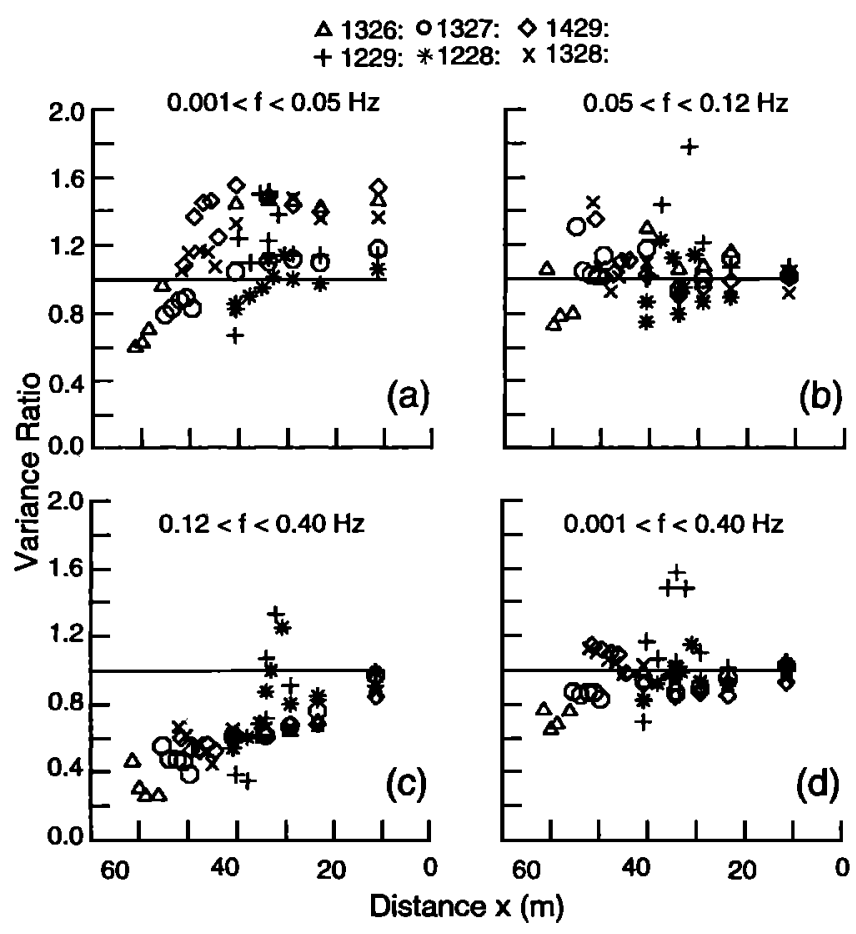

Figure 8. Ratio of predicted to observed band-passed sea surface elevation variance versus cross-shore distance for all six data runs. (a) $0.001 \leq f \leq 0.05$, (b) $0.05<f \leq 0.12$, (c) $0.12<f \leq 0.4$, and (d) $0.001 \leq f \leq 0.4 \mathrm{~Hz}$. 
tion of zero crossings predicted by the nonlinear model (about $x=40 \mathrm{~m}$ and $10 \mathrm{~m}$ in Figure 9b) does not differ substantially from linear theory predictions [e.g., $\mathrm{Hol}$ land et al., 1995, Figure 8c]. However, inviscid linear theory cannot predict the shoreward decay of wave energy at sea swell frequencies (Figure 7c-7f) nor the observed evolution of wave shapes (Figure 10).

The coupling between infragravity and sea swell waves was explored by initializing the model with a shoreward propagating wave field low-pass filtered to include only frequencies below $0.05 \mathrm{~Hz}$. The resulting predictions of infragravity energy at shoreward locations are compared to model predictions with both infragravity and sea swell energy in the initial conditions (Figure 11). Differences in the model predictions of infragravity waves at shoreward locations are ascribed to the (nonlinear) effect of sea swell energy on infragravity waves. (Note that two numerical simulations are compared to each other and not to field observations.) The absence of sea swell energy in the initial conditions of the 1328 run (Figure 11a) causes negligible difference
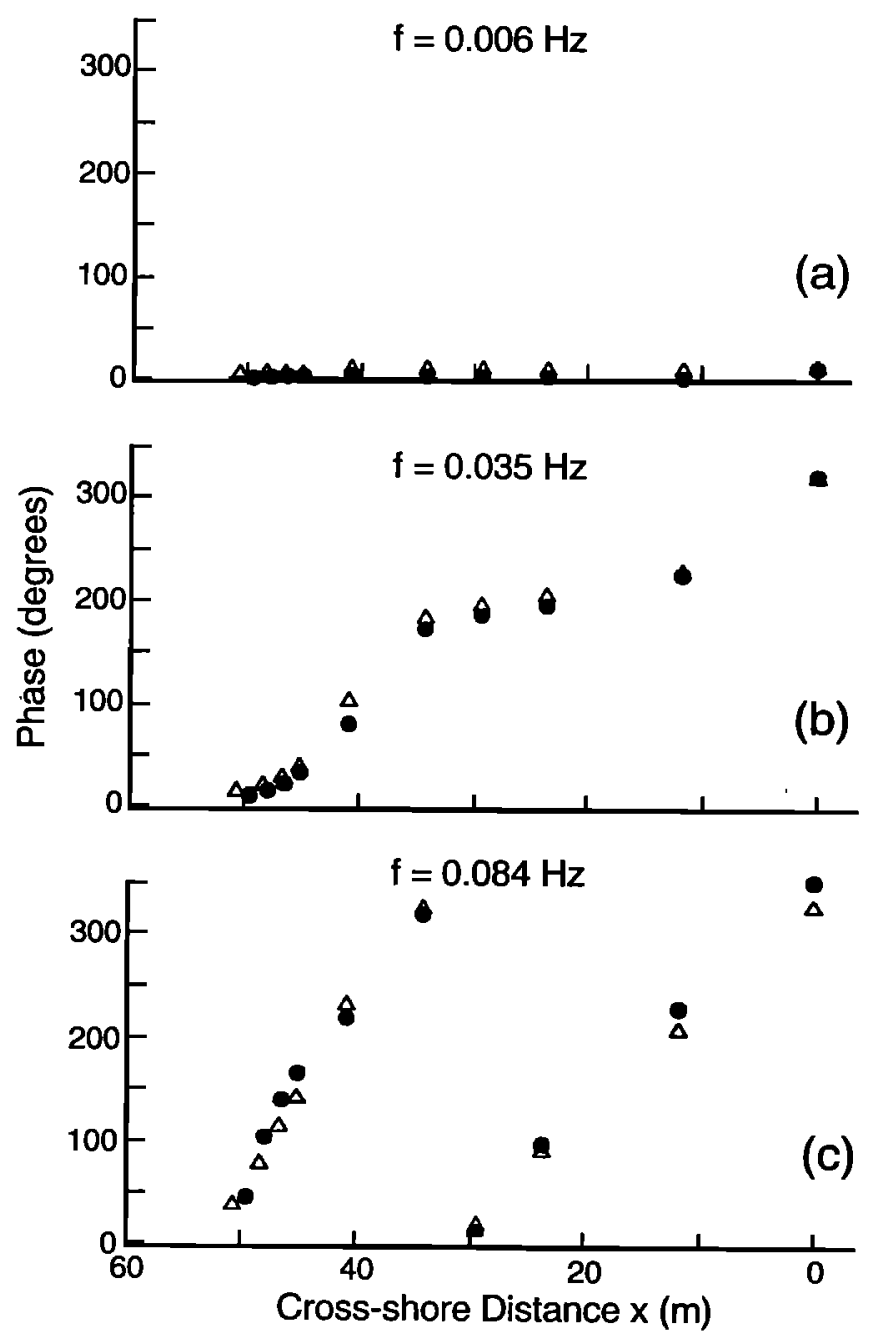

Figure 9. For run 1328, predicted (solid circles) and observed (open triangles) phase relative to R05 versus cross-shore distance for frequencies (a) 0.006 , (b) 0.035 , and (c) $0.084 \mathrm{~Hz}$. The bandwidth is $0.01 \mathrm{~Hz}$, and all coherences (not shown) are significant at the $95 \%$ level.

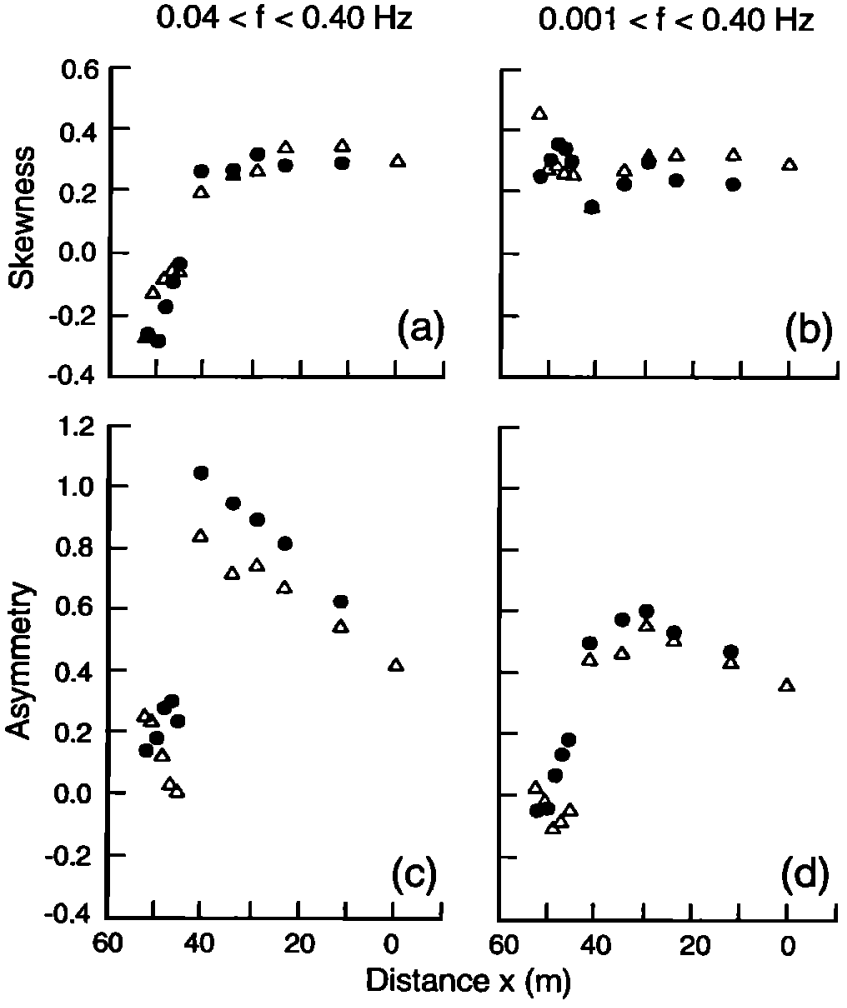

Figure 10. Predicted (solid circles) and observed (open triangles) (a-b) band-passed skewness and (c-d) asymmetry versus cross-shore distance for the 1328 run. Band-pass frequency ranges are $0.04<f \leq 0.40$ for Figures $10 \mathrm{a}$ and $10 \mathrm{c}$ and $0.001 \leq f \leq 0.40 \mathrm{~Hz}$ for Figures $10 \mathrm{~b}$ and $10 \mathrm{~d}$.

in the predicted cross-shore distribution of infragravity energy. Of the six runs, the maximum effect of the sea swell energy occurred in the 1229 run (Figure $11 b$ ). In this case, differences (more infragravity energy when sea swell energy is included) are consistent with generation of some infragravity energy by sea swell waves in the inner surf zone. In other cases (Figure 12a), there is less predicted energy in the infragravity band when sea swell energy is included, consistent with increased (nonlinear) dissipation of infragravity energy owing to the sea swell energy. Thus the presence of sea swell energy can (according to the present model) either increase or decrease the amount of infragravity energy, but in no case does the inclusion of sea swell energy cause predicted changes of more than $40 \%$ in the bandintegrated infragravity energy, and the effect is usually less than 20\% (Figure 12a). Although infragravity energy is likely generated by nonlinear processes involving sea swell waves in very shallow water [e.g., LonguetHiggins and Stewart, 1962], at least in some cases, (e.g., Figure 11a [Suhayda, 1974; Holland et al., 1995]) free waves appear to be the dominant infragravity motion in the inner surf zone. Herbers et al. [1994] recently showed that in $13 \mathrm{~m}$ depth the ratio of locally forced to free infragravity energy varied from less than $10^{-3}$ to 0.3 , with the amount of locally forced energy increasing with increasing swell energy. The present shallow water observations (and simulations) showing free wave dominance are limited to low swell conditions. 
Slope $=0.039$

Slope $=0.035$

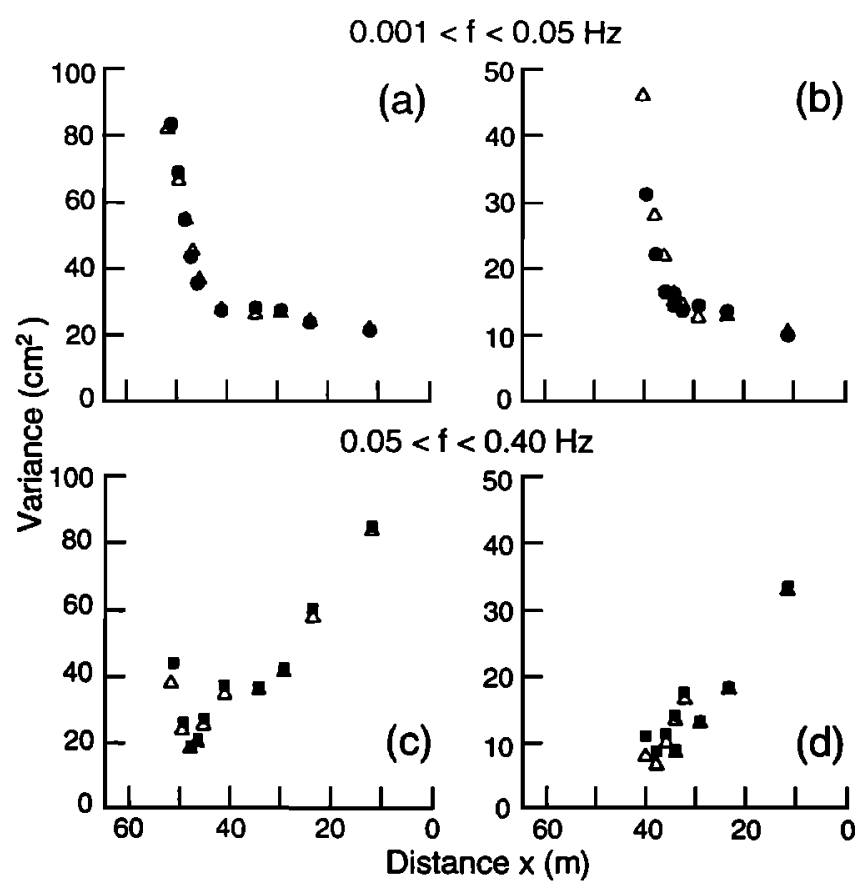

Figure 11. Predicted band-passed variance versus cross-shore distance: (a-b) low-frequency $(0.001 \leq f \leq$ $0.05)$; (c-d) high-frequency $(0.05<f \leq 0.40)$ predicted variance. Initial conditions are low-passed (0.001 $\leq f \leq$ 0.05 , solid circles), high-passed (0.05 $<f \leq 0.40$, solid squares), and total (0.001 $\leq f \leq 0.40$, open triangles) incident waves for data runs 1328 and 1229 having foreshore slopes 0.039 (Figures 11a and 11c) and 0.035 (Figures $11 \mathrm{~b}$ and $11 \mathrm{~d}$ ), respectively.

To assess the effect of infragravity energy on sea swell waves, a high-pass filter $(0.05 \leq f \leq 0.40 \mathrm{~Hz})$ was applied to the shoreward propagating wave field observed at the seaward boundary, thereby removing infragravity energy from the initial conditions. The predicted sea swell energy decays slightly more rapidly with infragravity energy present (Figures $11 \mathrm{c}$ and $11 \mathrm{~d}$ ), perhaps owing to increased (quadratic) friction, but differences in the local sea swell energy are usually less than $20 \%$ (Figure 12b). The simulations suggest a weak local interaction between infragravity and sea swell frequency waves in the inner surf zone, although these effects may be larger when energy levels are elevated above the relatively low levels considered here. Furthermore, although changes in the energy of one frequency band owing to energy in the other frequency band are small here, phase coupling between these frequency bands influences the wave skewness and asymmetry (compare Figure 10a with Figure 10b and Figure 10c with Figure 10d). Additional observations and modeling are needed to generalize these results to beach slopes and wave fields different than the narrow range considered here.

\section{Conclusions}

Numerical model predictions based on the onedimensional depth-averaged nonlinear shallow water equations with friction agree well with observations of surf zone sea surface fluctuations and run-up measured with a new multilevel wire sensor. In particular, the model accurately predicts that the increase of infragravity frequency $(0.001 \leq f \leq 0.05 \mathrm{~Hz})$ energy and decrease of sea swell frequency $(0.05<f \leq 0.40 \mathrm{~Hz})$ energy as waves propagate across the surf zone result in an energy minimum just seaward of the swash zone (Figure 7). The total variance of sea surface fluctuations and run-up is usually predicted with less than 20\% error (Figures $7 \mathrm{~g}, 7 \mathrm{~h}$, and $8 \mathrm{~d}$ ). Predicted and observed phase differences between sensors show that the amount of standing wave energy relative to progressive wave energy is large at infragravity frequencies and decreases with increasing frequency (Figure 9), consistent with predicted and observed reflection coefficients (Figure 2). Third moments (skewness and asymmetry) of the wave field, perhaps important to sediment transport, are also well predicted in the surf and swash zones (Figure 10). Model predictions suggest that local interactions between infragravity and sea swell waves are weak (Figures 11 and 12), consistent with the qualitative agreement previously noted at infragravity frequencies between this data set and an inviscid, linear standing wave model. The qualitative agreement between

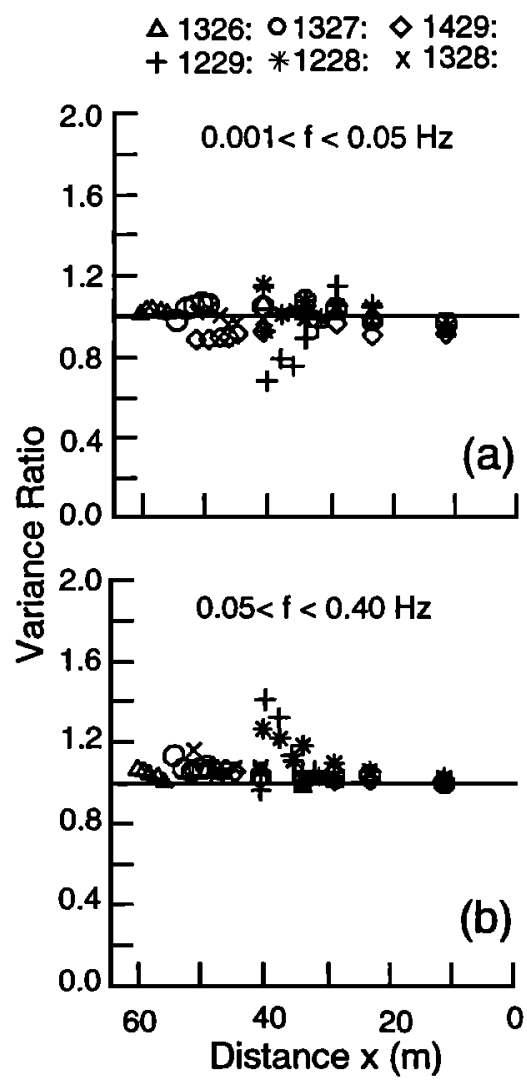

Figure 12. (a) For all six data runs, ratio of low-passed (e.g., infragravity) variance predicted with low-passed incident wave initial conditions to low-passed variance predicted with total incident wave initial conditions. (b) For all data runs, ratio of high-passed (e.g., sea swell) variance predicted with high-passed incident wave initial conditions to high-passed variance predicted with total incident wave initial conditions. 
predictions and observations (Figures 3-10) is consistent with the assumption that the effects of nonhydrostatic pressure, percolation, and three-dimensional motions (e.g., edge waves) are small, at least for the low energy waves, very shallow water, and fine-grained lowslope beach considered here.

\section{Appendix: Model Sensitivity to Friction and Step Size}

Run-up predictions may be affected by the value of the empirically determined friction coefficient. Previous limited calibrations of the model suggest $f_{c}=$ 0.05 or less on smooth slopes [e.g., Kobayashi et al., 1989; Kobayashi and Wurjanto, 1989; van der Meer and Breteler, 1990; Wise et al., 1991]. Cox et al. [1992] found that on a low-slope smooth beach, predictions of random waves in the surf zone were not sensitive to the value of $f_{c}$ if $0.01 \leq f_{c} \leq 0.05$, but swash zone motions were affected by the chosen $f_{c}$. Run-up spectra observed on a low-sloped natural beach were qualitatively predicted for $f_{c}=0.02$ but were underpredicted for $f_{c}=0.05$ [Kobayashi and Wurjanto, 1992].

To assess the effect of friction, predictions for a single data run are compared for friction factors $f_{c}$ between 0.01 and 0.05 . Higher friction tends to reduce bore and run-up heights (compare solid and dashed lines in Figures A1a-A1c), resulting in an overall decrease in variance (Figure A2a). The effect of friction increases as

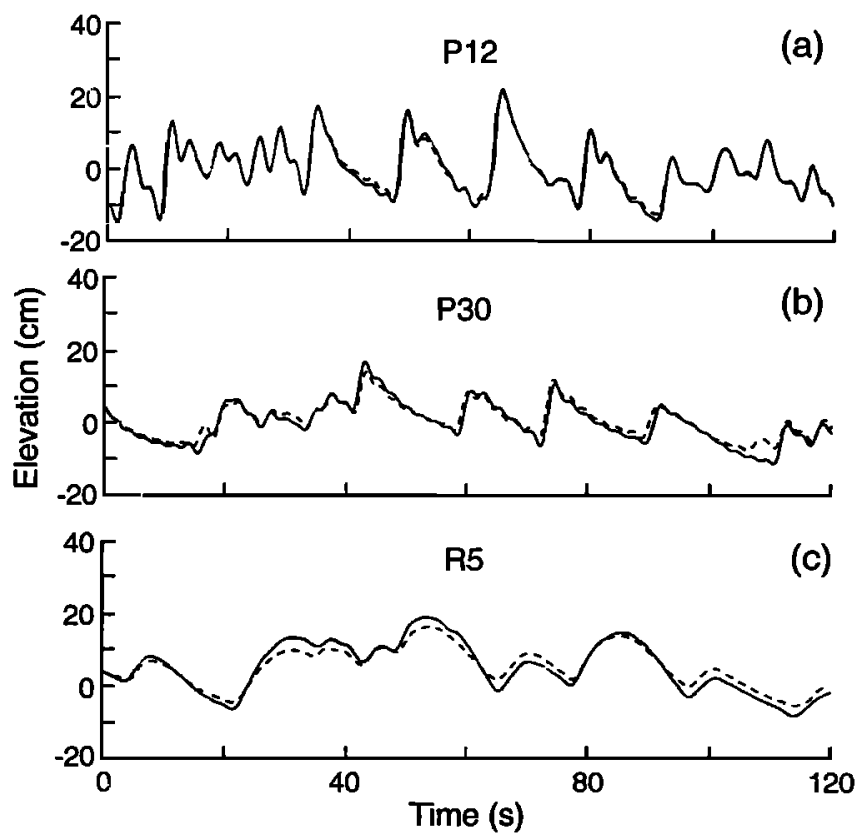

Figure A1. Predicted time series of sea surface elevation at cross-shore locations (a) $12 \mathrm{~m}$ and (b) $30 \mathrm{~m}$ and (c) of run-up $5 \mathrm{~cm}$ above the bed (mean horizontal location $42 \mathrm{~m}$ ) for different values of the friction coefficient, $f_{c}$, and normalized horizontal step size, $\Delta x^{\prime}$. Here $f_{c}=0.015$ and $\Delta x^{\prime}=0.01$ (solid line) $f_{c}=0.05$ and $\Delta x^{\prime}=0.01$ (dashed line), and $f_{c}=0.015$ and $\Delta x^{\prime}$ $=0.0025$ (dotted line). The dotted and solid lines are indistinguishable. The characteristic wave period and height at the seaward boundary are $6.8 \mathrm{~s}$ and $0.32 \mathrm{~m}$, respectively.
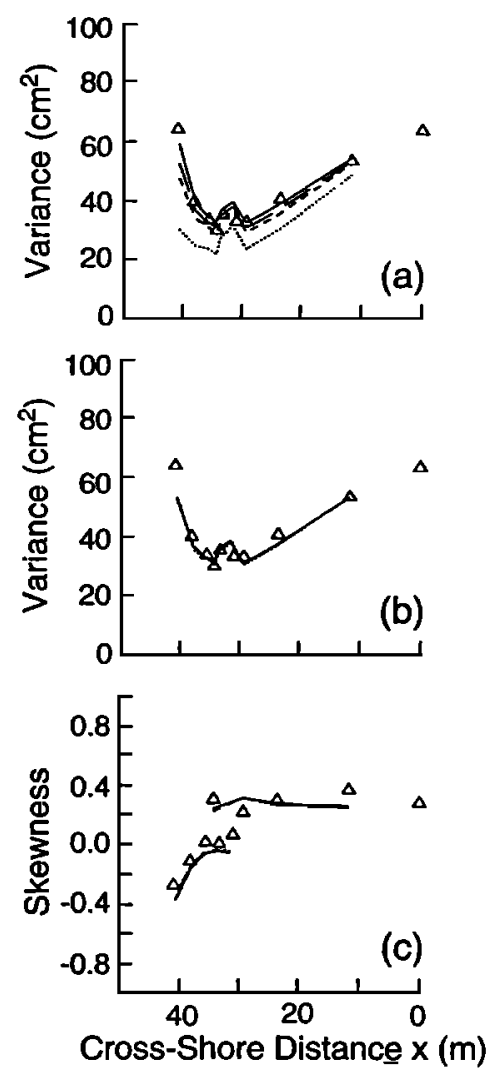

Figure A2. (a) Predicted variance for a normalized step size, $\Delta x^{\prime}$, of 0.01 and friction factor, $f_{c}$, of 0.010 (solid line), 0.015 (long-dashed line), 0.020 (short-dashed line), and 0.050 (dotted line) versus crossshore distance. Predicted (b) variance and (c) skewness for $f_{c}=0.015$ and $\Delta x^{\prime}=0.0025$ (solid line), 0.010 (long-dashed line), 0.020 (short-dashed line), and 0.030 (dotted line) versus cross-shore distance. The dotted, dashed, and solid lines are nearly identical. The characteristic wave period and height at the seaward boundary are $6.8 \mathrm{~s}$ and $0.32 \mathrm{~m}$, respectively. Observed variance and skewness (open triangles) are also shown.

the water depth decreases so that the greatest reduction in variance occurs in the run-up (Figures A1c and A2a).

Solutions of the depth-averaged nonlinear shallow water equations are valid across a shock if it is nearly vertical and covers only a relatively small distance. Since the Lax-Wendroff method spreads the bore front across a few horizontal grid points, the horizontal step size, $\Delta x$, must be small relative to the wave height and wavelength. Equivalently, the normalized step size, $\Delta x^{\prime}=\frac{\Delta x}{T \sqrt{g H}}$, where $T$ is the characteristic wave period, $H$ is the characteristic wave height, and $g$ is gravitational acceleration, must be much less than 1 . It has been suggested that the predicted time series and statistics of sea surface fluctuations and run-up may be sensitive to the step size even if the above criterion is satisfied because the step size affects the steepness of the bore front. However, comparison of model predictions using a plausible range of normalized step sizes shows that predicted time series, variance, and skewness are not significantly affected by the step size (Figures A1a, 
$\mathrm{A} 1 \mathrm{~b}$, and A1c; compare solid and dotted lines; Figures $A 2 b$ and A2c). A normalized step size of 0.01 was used for the present model predictions.

Acknowledgments. This study was funded by the ONR Coastal Dynamics Program, with additional support from NSF Physical Oceanography. B.R. was supported by an ONR NDSEG fellowship and the ONR AASERT program. The multilevel run-up meter was designed by Bob Lowe. Staff from the Center for Coastal Studies calibrated, deployed, and maintained the instruments.

\section{References}

Ames, W. F., Numerical Methods for Partial Differential Equations, 291pp., Barnes and Noble, New York, 1969.

Carrier, G. F., and H. P. Greenspan, Water waves of finite amplitude on a sloping beach, J. Fluid Mech., 4, 97-109, 1958.

Cox, D. T., N. Kobayashi, and A. Wurjanto, Irregular wave transformation processes in surf and swash zones, paper presented at the 23rd International Conference on Coastal Engineering, Am. Soc. of Civ. Eng., Venice, 1992.

Elgar, S., and R. T. Guza, Shoaling gravity waves: Comparisons between field observations, linear theory, and a nonlinear model, $J$. Fluid Mech., 158, 47-70, 1985.

Elgar, S., M. H. Freilich, and R. T. Guza, Model-data comparisons of moments of nonbreaking shoaling surface gravity waves, J. Geophys. Res., 95, 16,055-16,063, 1990.

Elgar, S., T. H. C. Herbers, and R. T. Guza, Reflection of ocean surface gravity waves from a natural beach, $J$. Phys. Oceanogr., 24, 1503-1522, 1994.

Guza, R. T., and A. J. Bowen, Resonant interactions for waves breaking on a beach, paper presented at the 15 th International Conference on Coastal Engineering, Am. Soc. of Civ. Eng., Honolulu, 1976.

Guza, R. T., and E. B. Thornton, Velocity moments in nearshore, J. Water Port Coastal Ocean Eng., 111, 235256, 1985a.

Guza, R. T., and E. B. Thornton, Observations of surf beat, J. Geophys. Res., 90, 3161-3172, 1985b.

Guza, R. T. , E. B. Thornton, and R.A. Holman, Swash on steep and shallow beaches, paper presented at the 19th International Conference on Coastal Engineering, Am. Soc. of Civ. Eng., Houston, Texas, 1984.

Herbers, T. H. C., S. Elgar, and R. T. Guza, Infragravityfrequency (0.005-0.05 Hz) motions on the shelf, $I$, Forced waves, J. Phys. Oceanogr., 24, 917-927, 1994.

Hibberd, S., and D. H. Peregrine, Surf and run-up on a beach, J. Fluid Mech., 95, 323-345, 1979.

Holland, K. T., B. Raubenheimer, R. T. Guza, and R. Holman, Runup kinematics on a natural beach, J. Geophys. Res., in press, 1995.

Holman, R. A., and R. T. Guza, Measuring run-up on a natural beach, Coastal Eng., 8, 129-140, 1984.

Holman, R. A., and A. H. Sallenger, Setup and swash on a natural beach, J. Geophys. Res., 90, 945-953, 1985.

Huntley, D. A., Long period waves on a natural beach, $J$. Geophys. Res., 81, 6441-6449, 1976.

Huntley, D., R. T. Guza, and A. J. Bowen, A universal form for shoreline run-up spectra?, J. Geophys. Res., 82, 2577$2581,1977$.

Keller, H. B., D. A. Levine, and G. B. Whitham, Motion of a bore over a sloping beach, J. Fluid Mech., 7, 302-316, 1960.

Kobayashi, N., and A. Wurjanto, Wave overtopping on coastal structures, J. Water Port Coastal Ocean Eng., $115,235-251,1989$

Kobayashi, N., and A. Wurjanto, Irregular wave setup and run-up on beaches, J. Water Port Coastal Ocean Eng., 118, 368-386, 1992.

Kobayashi, N., G. S. DeSilva, and K. D. Watson, Wave transformation and swash oscillation on gentle and steep slopes, J. Geophys. Res., 94, 951-966, 1989.
Kobayashi, N., D. T. Cox, and A. Wurjanto, Irregular wave reflection and run-up on rough impermeable slopes, $J$. Water Port Coastal Ocean Eng., 116, 708-728, 1990.

Lax, P., and B. Wendroff, Systems of conservation laws, Commun. Pure Appl. Math., 13, 217-237, 1960.

List, J., A model for the generation of two-dimensional surf beat, J. Geophys. Res., 97, 5623-5635, 1992.

Longuet-Higgins, M. S., and R. W. Stewart, Radiation stress and mass transport in surface gravity waves with application to "surf beats", J. Fluid Mech., 13, 481-504, 1962.

Madsen, P. A., and I. A. Svendsen, Turbulent bores and hydraulic jumps, J. Fluid Mech., 129, 1-25, 1983.

Masuda, A., and Y. Y. Kuo, A note on the imaginary part of bispectra, Deep Sea Res., 28A, 213-222, 1981.

Meyer, R. E., and A. D. Taylor, Run-up on beaches, in Waves on Beaches and Resulting Sediment Transport, edited by R. E. Meyer, pp. 357-411, Academic, San Diego, Calif., 1972.

Miche, R., Le pouvoir réfléchissant des ouvrages maritimes exposés à l'action de la houle, Ann. Ponts Chaussees, 121, 285-319, 1951.

Moraes, C., Experiments of wave reflection on impermeable slopes, paper presented at the 12th International Conference on Coastal Engineering, Am. Soc. of Civ. Eng., Washington, D.C., 1970.

Nagata, Y., The statistical properties of orbital wave motions and their application for the measurement of directional wave spectra, J. Oceanogr. Soc. Jpn., 19, 169-181, 1964.

Oltman-Shay, J., and R. T. Guza, Infragravity edge wave observations on two California beaches, J. Phys. Oceanogr., 17, 644-663, 1987

Packwood, A. R., Surf and run-up on beaches, Ph.D. thesis, 178 pp., Univ. of Bristol, School of Math., Bristol, England, 1980.

Ritchmyer, R. D., and K. W. Morton, Difference Methods for Initial-Value Problems, 2nd ed., 354 pp., WileyInterscience, New York, 1967.

Shen, M. C., and R. E. Meyer, Climb of a bore on a beach, 3, Run-up, J. Fluid Mech., 74, 685-694, 1963.

Suhayda, J. N., Standing waves on beaches, J. Geophys. Res., 79, 3065-3071, 1974.

Synolakis, C. E., The run-up of solitary waves, J. Fluid Mech., 185, 523-545, 1987.

van der Meer, J. W., and M. K. Breteler, Measurement and computation of wave induced velocities on a smooth slope, paper presented at the 22nd International Conference on Coastal Engineering, Am. Soc. of Civ. Eng., Delft, Netherlands, 1990.

Wise, R. A., N. Kobayashi, and A. Wurjanto, Cross-shore sediment transport under irregular waves in surf zones, paper presented at Coastal Sediments '91, Am. Soc. of Civ. Eng., Seattle, Wash., 1991.

Wurjanto, A., and N. Kobayashi, Numerical model for random waves on impermeable coastal structures and beaches, Res. Rep. CACR-91-05, Cent. for Appl. Coastal Res., Univ. of Delaware, Newark, 1991.

Steve Elgar, Electrical Engineering and Computer Science, Washington State University, Pullman, WA 991642752. (email: elgar@eecs.wsu.edu)

R. T. Guza and B. Raubenheimer, Center for Coastal Studies, Scripps Institution of Oceanography, La Jolla, CA 92093-0209. (email: rtg@coast.ucsd.edu; britt@coast.ucsd.edu)

N. Kobayashi, Department of Civil Engineering, University of Delaware, Newark, DE 19716. (email: nk@coastal.udel.edu)

(Received May 16, 1994; revised October 19, 1994; accepted October 20, 1994.) 